University of Nebraska - Lincoln

DigitalCommons@University of Nebraska - Lincoln

2005

\title{
Carbon Nanotubes with Covalently Linked Porphyrin Antennae: Photoinduced Electron Transfer
}

\author{
Durairaj Baskaran \\ University of Tennessee - Knoxville \\ Jimmy W. Mays \\ University of Tennessee - Knoxville \\ X. Peter Zhang \\ University of Tennessee - Knoxville \\ Matthew S. Bratcher \\ U.S. Army Research Laboratory, Weapons and Materials Research Directorate
}

Follow this and additional works at: https://digitalcommons.unl.edu/usdoepub

Part of the Bioresource and Agricultural Engineering Commons

\footnotetext{
Baskaran, Durairaj; Mays, Jimmy W.; Zhang, X. Peter; and Bratcher, Matthew S., "Carbon Nanotubes with Covalently Linked Porphyrin Antennae: Photoinduced Electron Transfer" (2005). US Department of Energy Publications. 32.

https://digitalcommons.unl.edu/usdoepub/32

This Article is brought to you for free and open access by the U.S. Department of Energy at DigitalCommons@University of Nebraska - Lincoln. It has been accepted for inclusion in US Department of Energy Publications by an authorized administrator of DigitalCommons@University of Nebraska - Lincoln.
} 


\title{
Carbon Nanotubes with Covalently Linked Porphyrin Antennae: Photoinduced Electron Transfer
}

\author{
Durairaj Baskaran, ${ }^{*, \dagger}$ Jimmy W. Mays, ${ }^{\dagger}, \S$ X. Peter Zhang, ${ }^{\dagger}$ and Matthew S. Bratcher ${ }^{\ddagger}$ \\ Department of Chemistry, University of Tennessee, 552 Buehler Hall, Knoxville, Tennessee 37996, Chemical \\ Sciences Division, Oak Ridge National Laboratory, Oak Ridge, Tennessee 37831, and U.S. Army Research \\ Laboratory, Weapons and Materials Research Directorate, AMSRL-WM-MA, APG, Maryland 21005
}

Received February 8, 2005; E-mail: baskaran@utk.edu

Functionalization of carbon nanotubes through surface modification has attracted significant interest recently. ${ }^{1-5}$ Covalent and noncovalent functionalization strategies involving reactions of organic or polymeric molecules onto carbon nanotubes have primarily focused on dispersion or dissolution properties. Incorporation of light absorbing antenna chromophores through a covalent linkage with the extended $\pi$ electrons of a carbon nanotube would constitute an ideal supramolecular nanoassembly for generating singlet excited energy and its conversion to chemical energy. Porphyrins are one such class of molecules used in assemblies of donor-acceptor materials in molecular electronics and photovoltaic devices. ${ }^{6}$

Several fullerene-based molecular systems with covalently linked porphyrins and metalloporphyrins have been synthesized; their interesting photoinduced electron-transfer processes have been studied. ${ }^{6-8}$ Noncovalent interaction of metalloporphyrins and freebase porphyrins with single-wall carbon nanotubes (SWNTs) has been used for dispersion and also for separation of semiconducting and metallic tubes. ${ }^{9}, 10$ Recently, a noncovalently interacting donoracceptor system consisting of an anionically functionalized porphyrin and a cationically functionalized pyrene stacked on SWNTs has been shown to exhibit electron-transfer properties. ${ }^{11}$ A donoracceptor system with a covalent linkage between the light-harvesting antenna and the acceptor reaction center could enhance the efficiency of photoinduced electron transfer and energy transfer. Supramolecular structures consisting of covalently grafted porphyrins to carbon nanotubes have not been synthesized so far as an efficient donor-acceptor system. In this communication, we report the synthesis of meso-substituted porphyrin-grafted carbon nanotubes ((por) $n_{n}-g$-CNTs), including multiwalled nanotubes ((por $)_{n}-g$ MWNTs) and SWNT ((por) $)_{n}-g$-SWNTs), and the study of their photoinduced electron-transfer properties.

We used surface-bound carboxylic acid groups $(\sim 1 \mathrm{~mol} \%)$ of MWNTs and SWNTs to attach a functional porphyrin, 5-phydroxyphenyl-10,15,20-tritolylporphyrin (por-OH). ${ }^{12}$ HiPco SWNTs were purified using stepwise wet-air oxidation and shortened using a sulfuric acid/nitric acid (3:1) treatment. First, carbon nanotubes treated with thionyl chloride were reacted with excess por-OH in toluene in the presence of triethylamine at $100{ }^{\circ} \mathrm{C}$ for $24 \mathrm{~h}$ under a pure nitrogen atmosphere. To remove the unreacted por- $\mathrm{OH}$, the tubes were washed thoroughly with plenty of methanol, followed by a small amount of acetic acid and triethylamine, and finally with tetrahydrofuran (THF). The (por) ${ }_{n}-g$-CNTs were then dried at $40{ }^{\circ} \mathrm{C}$ for $5 \mathrm{~h}$ under vacuum.

The FTIR spectrum of the porphyrin-attached carbon nanotubes (Scheme 1) showed characteristic vibrations of pyrrole, methyl, and aromatic groups centered at 1200, 2922, and $3010 \mathrm{~cm}^{-1}$, respectively. The quantity of porphyrin attached to the surface was determined from thermogravimetric analysis (TGA), which showed a gradual weight loss starting from 200 to $625^{\circ} \mathrm{C}$, with a major weight loss at $596^{\circ} \mathrm{C}$. The decompositions in the temperature ranges

\footnotetext{
$\dagger$ University of Tennessee.

$\S$ Oak Ridge National Laboratory.

* U.S. Army Research Laboratory.
}

Scheme 1. Porphyrin-Grafted Carbon Nanotubes and the Photoinduced Electron Transfer

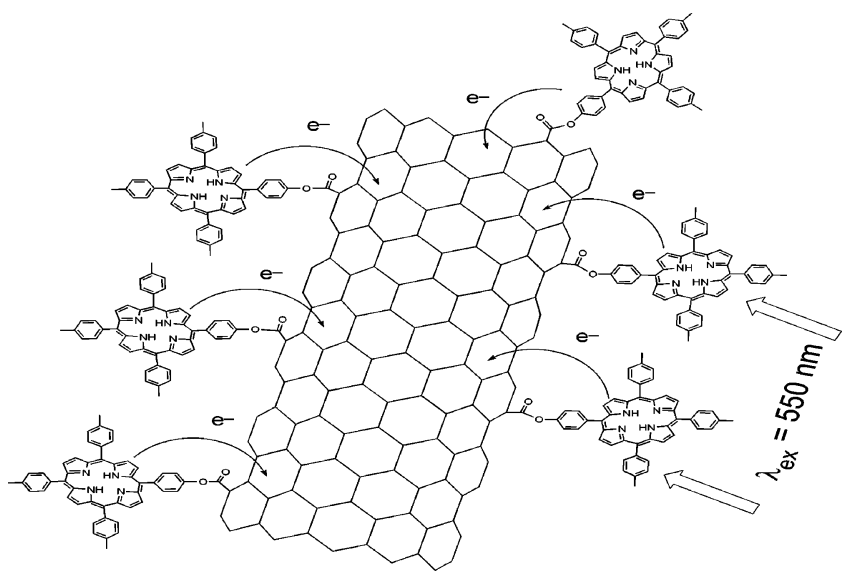

from 200 to $500{ }^{\circ} \mathrm{C}$ and 500 to $625^{\circ} \mathrm{C}$ were assigned to the attached porphyrin and the MWNTs, respectively (Figure 1a). The amount of porphyrin grafted to the tubes varies from 8 to $22 \%$ depending on the concentration of por- $\mathrm{OH}$ used for the reaction (Table 1). The weight $\%$ of porphyrin is slightly underestimated due to the fact that the decomposition of por-OH merges with MWNTs$\mathrm{COOH}$. A mole percent of porphyrin linked to the MWNTs was calculated using the weight $\%$ from the TGA and found to be in the range of $10-40 \%$ with respect to the acid groups of the tubes.

The (por) ${ }_{n}-g$-CNTs are soluble in chloroform, THF, and dichloromethane. A slow aggregation of (por) $)_{n}-g$-CNTs was noticed when the concentration of the dispersion was greater than $35 \mathrm{mg} / \mathrm{L}$. The UV-vis absorption in chloroform showed a broad signal monotonically decreasing from 300 to $900 \mathrm{~nm}$ and a Soret band at $450 \mathrm{~nm}$ corresponding to the carbon nanotubes and the porphyrin, respectively (Figure 1b). Interestingly, the absorption of surface-grafted porphyrin had a distinct shift $\left(\Delta \lambda_{\max } \sim 28 \mathrm{~nm}\right)$ as compared to that of the por-OH. At these wavelengths, competitive absorbance by SWNTs at a low concentration is minimal. In the case of (por) $n^{-}$ $g$-MWNTs samples, only the Soret band was seen at $450 \mathrm{~nm}$ due to the overwhelmingly broad absorption of MWNTs. However, in the case of (por) $n_{n}-g$-SWNTs, both the Soret and Q-bands were seen clearly. The pattern of Q-bands suggests that covalently linked porphyrins exist in a protonated form. It appears that the residual acid groups of the carbon nanotubes are interacting with the grafted porphyrins in solution. A solid-state UV absorbance of (por) $n_{n}^{-} g_{-}$ MWNTs exhibits the Soret band at $423 \mathrm{~nm}$ corroborating the presence of protonated porphyrin in the solution (Supporting Information). Addition of a drop of triethylamine into the solution also shifts the Soret band back to $423 \mathrm{~nm}$, which confirms the equilibrium nature of the protonation mechanism (Supporting Information). Although noncovalently adsorbed (or) complexed porphyrins with SWNTs do not show a major shift in the Soret band, ${ }^{9,11}$ it is 

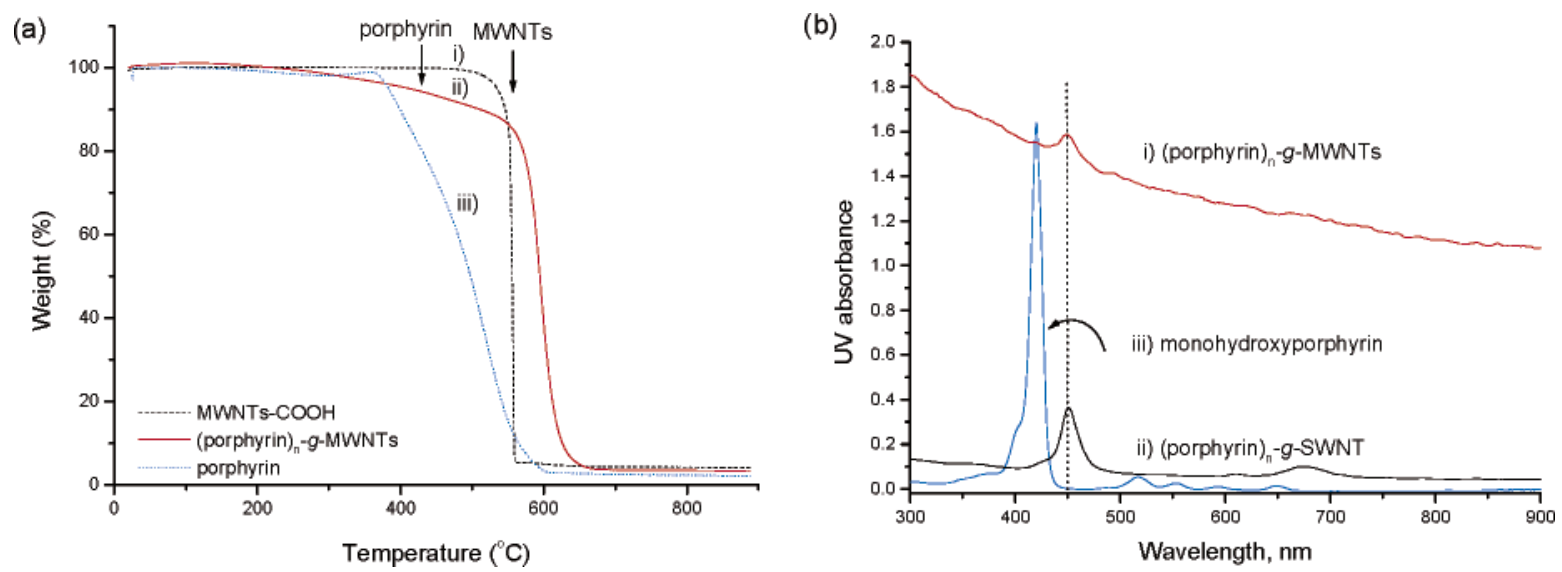

Figure 1. (a) TGA of (por) $n_{n}$ - $-\mathrm{MWNTs}$ showing porphyrin decomposition from 200 to $500{ }^{\circ} \mathrm{C}$; (i) precursor MWNTs-COOH, (ii) porphyrin-attached MWNTs $\left(9.6 \mathrm{wt} \%\right.$ ), and (iii) por-OH. (b) UV-vis absorbance of (por) $n_{n}$-g-MWNTs solutions in $\mathrm{CHCl}_{3}$; (i) (por) $n^{-}$-g-MWNTs (Table 1 , run 2 , 33 mg/L), (ii) (por) $n_{n}-g$-SWNTs (Table 1 , run $3,3 \mathrm{mg} / \mathrm{L}$ ), and (iii) por-OH $(2.5 \mathrm{mg} / \mathrm{L})$.

Table 1. Grafting of Porphyrin onto Carbon Nanotubes

\begin{tabular}{lccccc}
\hline & & \multicolumn{4}{c}{ Porphyrin-g-Carbon Nanotubes } \\
\cline { 3 - 6 } \multicolumn{1}{c}{ CNTs } & $\begin{array}{c}\text { [por-OH]/ } \\
{[\text { CNT - COCl] }]^{a}}\end{array}$ & $\begin{array}{c}w^{*} \%^{b} \\
\text { porphyrin }\end{array}$ & $\begin{array}{c}\text { mol \% }{ }^{c} \\
\text { porphyrin }\end{array}$ & $\begin{array}{c}\Delta \lambda_{\text {max }}{ }^{d} \\
\text { red shift }\end{array}$ & $\begin{array}{c}\%^{e} \\
\text { quenching }\end{array}$ \\
\hline MWNTs-1 & 1.1 & 8.3 & 0.15 & 30 & 97 \\
MWNTs-2 & 2.5 & 9.6 & 0.17 & 28 & $\sim 100$ \\
SWNTs-1 & $>1.0$ & $22.0^{f}$ & 0.40 & 31 & 96 \\
\hline
\end{tabular}

${ }^{a}$ Ratio of por-OH to acid chloride groups of CNTs calculated on the basis of $1 \mathrm{~mol} \%$ acid. ${ }^{b}$ Obtained from TGA in air. ${ }^{c}$ Porphyrin mol $\%=$ (mol of porphyrin by TGA $\times 12$ ). ${ }^{d}$ Shifts of UV absorbance maximum of (por) ${ }_{n}$ - $g$-CNTs with reference to porphyrin in $\mathrm{CHCl}_{3} .{ }^{e}$ Determined from the ratio of fluorescence emission $\left(\lambda_{\mathrm{ex}}=550 \mathrm{~nm}\right)$ of porphyrin versus (por $)_{n-}$ $g$-CNTs at a matching absorbance. ${ }^{f}$ Weight $\%$ determined by the UV absorbance on the basis of apparent molar extinction coefficients of porphyrin and SWNTs. ${ }^{13}$

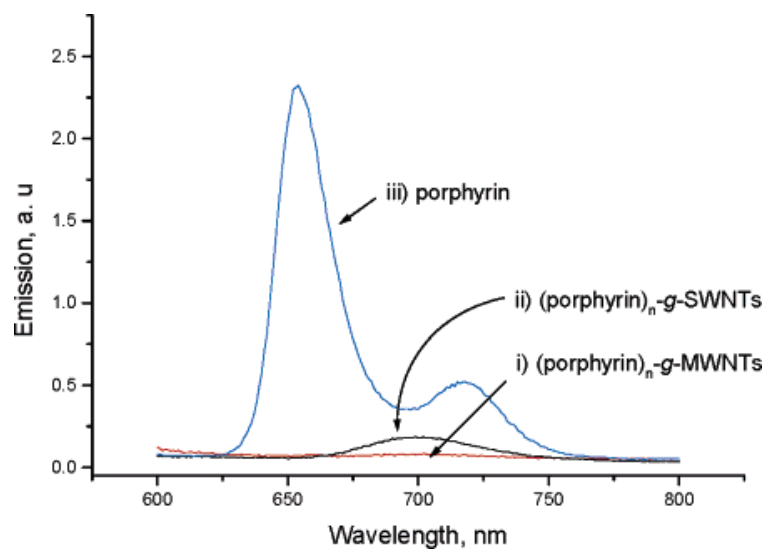

Figure 2. Steady-state fluorescence of (i) (por) $n_{n}^{-} g$-MWNTs, (ii) (por) $n_{n}-g$ SWNTs, and (iii) por-OH in $\mathrm{CHCl}_{3}$ at $\lambda_{\mathrm{ex}}=550 \mathrm{~nm}$. The Soret band absorbance of $[\text { por }]_{\mathrm{abs}}=0.183,\left[(\text { por })_{n}-\mathrm{g}-\mathrm{MWNTs}\right]_{\mathrm{abs}}=0.183$, and $\left[(\text { por })_{n-}\right.$ $g$-SWNTs $]_{\text {abs }}=0.364$.

difficult to ascertain the presence of ground-state interaction between the $\pi$ systems in (por) ${ }_{n}-g$-CNTs due to proton transfer.

The covalently connected porphyrins on carbon nanotubes can be used as energy transporting antennae. Upon excitation at 550 $\mathrm{nm}$, the solution of (por) ${ }_{n}-g$-CNTs exhibits $\sim 95-100 \%$ quenching of emission bands at 650 and $725 \mathrm{~nm}$, as compared to that of por$\mathrm{OH}$ at a matching absorption (Figure 2). Excitation at different wavelengths $(400,450$, and $500 \mathrm{~nm})$ also showed a similar quenching, supporting the presence of an electron-transfer process (Supporting Information). The intensity of the emission bands increased with the addition of an equimolar amount of free porphyrin into the solution of (por) $n_{n}-g$-SWNTs, indicating the absence of intermolecular electron transfer (Supporting Informa- tion). The electron transfer from singlet excited porphyrins to carbon nanotubes takes place only when the porphyrins are linked covalently, as evidenced by a substantial emission quenching. This reveals that covalently connected porphyrins act as energy absorbing and electron transferring antennae, and the carbon nanotubes act as electron acceptors.

In conclusion, MWNTs and SWNTs with covalently linked porphyrin antennae have been synthesized and characterized as potential supramolecular donor-acceptor complexes. The absorption and fluorescence of these complexes show that the carbon nanotubes serve as an efficient electron acceptor and pave the way to construct novel photovoltaic devices and light-harvesting systems using various porphyrin-functionalized carbon nanotubes.

Acknowledgment. We thank the U.S. Army (DAAD19-01-2002) and DOE (DE-AC05-00OR22725) for financial support.

Supporting Information Available: Synthesis of (por) $n_{n}-g$-CNTs, UV-vis spectra of (por) $n_{n}^{-} g$-MWNTs in solid-state and (por) $n_{n}-g$-SWNTs before and after triethylamine in solution, emission spectra at $\lambda_{\mathrm{ex}} 400$ and $450 \mathrm{~nm}$, in the presence of free porphyrin, purification of HiPco SWNTs (TGA, SEM, and TEM), and Raman spectrum of porphyrinlinked carbon nanotubes. This material is available free of charge via the Internet at http://pubs.acs.org.

\section{References}

(1) Chen, J.; Hamon, M. A.; Hu, H.; Chen, Y.; Rao, A. M.; Eklund, P. C.; Haddon, R. C. Science 1998, 282, 95-98.

(2) Sun, Y.-P.; Fu, K.; Lin, Y.; Huang, W. Acc. Chem. Res. 2002, 35, 10961104 .

(3) O'Connell, M. J.; Boul, P. J.; Ericson, L. M.; Huffman, C. B.; Wang, Y.; Haroz, E. H.; Kuper, C.; Tour, J. M.; Ausman, K. D.; Smalley, R. E. Chem. Phys. Lett. 2001, 342, 265-271.

(4) Baskaran, D.; Mays, J. W.; Bratcher, M. S. Angew. Chem., Int. Ed. 2004, $43,2138-2142$

(5) Xu, Y.; Gao, C.; Kong, H.; Yan, D.; Jin, Y. Z.; Watts, P. C. P. Macromolecules 2004, 37, 8846-8853.

(6) Gust, D.; Moore, T. A. In The Porphyin Handbook; Kadish, K. M., Smith, K. M., Guilard, R., Eds.; Academic Press: New York, 2000; Vol. 8, pp $153-190$.

(7) D'Souza, F.; Smith, P. M.; Zandler, M. E.; McCarty, A. L.; Itou, M.; Araki, Y.; Ito, O. J. Am. Chem. Soc. 2004, 126, 7898-7907.

(8) Sutton, L. R.; Scheloske, M.; Pirner, K. S.; Hirsch, A.; Guldi, D. M.; Gisselbrencht, J.-P. J. Am. Chem. Soc. 2004, 126, 10370.

(9) Murakami, H.; Nomura, T.; Nakashima, N. Chem. Phys. Lett. 2003, 378 , $481-485$.

(10) Li, H.; Zhou, B.; Lin, Y.; Gu, L.; Wang, W.; Fernando, S.; Kumar, S.; Allard, L. F.; Sun, Y.-P. J. Am. Chem. Soc. 2004, 126, 1014-1015.

(11) Guldi, D. M.; Rahman, G. M. A.; Jux, N.; Tagmatarchis, N.; Prato, M. Angew. Chem., Int. Ed. 2004, 43, 5526-5530.

(12) Zhang, X.-X.; Wayland, B. B. J. Am. Chem. Soc. 1994, 116, 7897-7898.

(13) Bahr, J. L.; Mickelson, E. T.; Bronikowski, M. J.; Smalley, R. E.; Tour, J. M. Chem. Commun. 2001, 193-194.

JA0508222 